\title{
The Design of Vending Machine Simulated System
}

\author{
Biqing $\mathrm{Li}^{1, \text { a }}$, Zhao $\mathrm{Li}^{2,}{ }^{2,}$, , Shanshan Liang ${ }^{1, \mathrm{a}}$ \\ ${ }^{1}$ College of Mechanical and Electronic Engineering, Hezhou University, Hezhou Guangxi 542899, \\ China; \\ ${ }^{2}$ Management Engineering Department, Guangxi vocational and technical college of \\ communications, Liuzhou Guangxi 545000, China; \\ ajanliful@163.com, b229292710@qq.com
}

Keywords: words: vending machine; AT89S52; micro controller; matrix key bord; LCD1602

\begin{abstract}
This page proposed a vending machine simulation system which used MCU AT89S52 as the core. In this paper, The design process, hardware selection and software design process of the vending machine system are introduced in detail, and expounds the basic principles of design. The system can be realized automatic control process of the vending machine, simulated insert coins and choice of goods by using a 4 x 4 matrix keyboard key, displayed goods selected number and the number of currencies by using LCD1602. The system has very high use value with the advantages of simple design.
\end{abstract}

\section{Design}

(1)This vending machine can sell three commodities including water, G-tea and coffee.

(2)After the customer inserted the coin (banknote) in 1Yuan, 5 Yuan or 10 Yuan (by pressing the button for simulation), the LCD1602 will display the coin (banknote) amount accordingly.

(3Once the coin (banknote) was enough, the machine will deliver the commodity automatically (the delivered commodity shall be simulated with different indicator lights), meanwhile return the change accordingly, the change amount will be displayed by LCD1602.

(4) it's assumed that there's no limit on both the commodity inventory and change;

(5)The customer can only buy one commodity at a time, further needs for other commodities may need the repeated operation accordingly.

\section{Design Principle and Scheme Selection}

\subsection{The Working Principle of Vending Machine}

(1)To insert the money into slot, then the sensor will collect the data and the identifier will judge whether the money was fake and the matching amount;

(2)The identifier will transfer the information and data to the communication module.

(3)The communication module will communicate with the main control system of vending machine, the main control system then displays the money amount, to start the panel button on the vending machine, showing which channel contains the commodity and which one is empty, then waiting for customers choice through pressing button;

(4)After the customer selected the commodity, the vending machine will deliver the commodity automatically for pick-up.

(5)To show the balance amount, if the balance amount was enough, the customer can also select to get the change or continue buying commodity; if the balance amount was not enough, the vending machine will return the change after a while. The returned change can be delivered in two types: the one is the bank note sent by the identifier; another one is the coin returned by coin communication module.

\subsection{Hardware Circuit}

In this paper, the designed vending machine has total 16 buttons arranged in $4 \times 4$ matrix form named as 1 to 16 from the left to the right side, and one LCD1602 display, 4 LED lights and warning 
system. Thereinto, button no. 1-3 are used to simulate the inserted 1 Yuan, 5 Yuan and 10 Yuan currency respectively, button no. 5-7 are used to simulate the selected commodity as water, G-tea and coffee respectively, button no. 9-11 are the multi-choice button, to represent purchasing 2, 3 or 4 commodities at one time. Button no. 4, 8, 12,16 are the function buttons, to represent starting use, cancellation, return money and confirming respectively. The remained 3 buttons are used to adjust commodity price, thereinto, button no. 15 means to start the price adjustment, 4and button no. 13 and 14 represent adding one item or reducing one item respectively.

\subsection{The Introduction for Main Components}

In this design, the central control component used AT89S52 of the series MCS-52 SCM. AT89S52 is the 8-digit CMOS micro controller with lower energy consumption and high performance, it has the $8 \mathrm{~K}$ in-system programmable flash memory, manufactured with the high density nonvolatile memory technology of Atmel company, compatible with the industrial 90C51 product instruction and pins completely. Its flash on the chip can allow in-system programming of program memory, and it can also applicable for conventional programmer.

\section{The Design for Control System of Vending Machine}

\subsection{Hardware System Design}

(1)The design of determinant button modules

As above mentioned, the P1 port of AT89S52 connects with total 16 buttons in $4 \mathrm{x} 4$ determinant. At the first line, these button can be named as button no.1, 2, 3 and 4 respectively from the left to the right side, then the other remained buttons and so on.
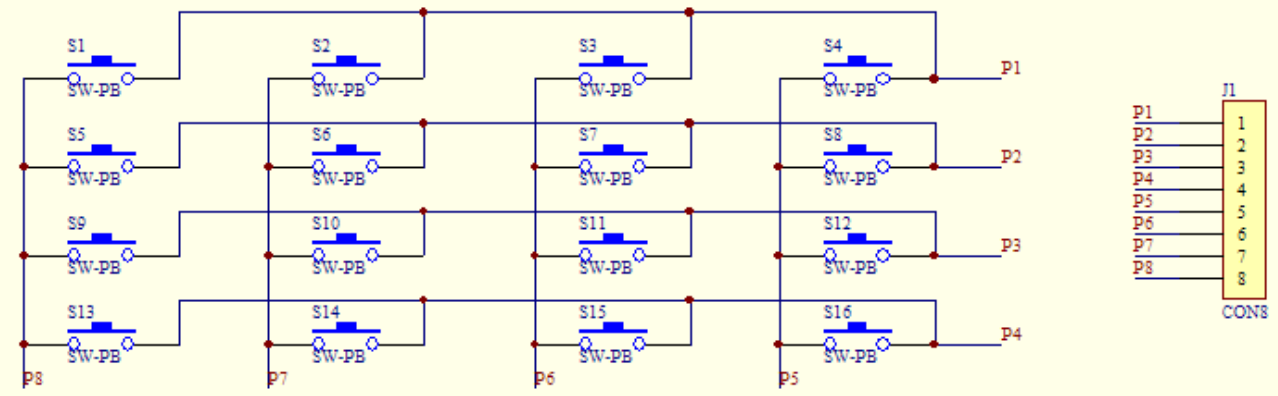

Figure 1. The circuit diagram of button module

(2)The design of money inserting system

The money inserting system shall be relatively important part in the design of vending machine, it involves the currency identification system, here it has no further research on how to design the currency identifier and how does the currency identifier work. In this design, its aim is mainly to realize the functions of vending machine such as amount display of totally inserted money, commodity selection, commodity delivery and returning change. So that in this design it uses 3 buttons to represent the inserted 1 Yuan, 5 Yuan and 10 Yuan, thereinto, button no. 1 represents 1 Yuan, no. 2 represents 5 Yuan and no. 3 represents 10 Yuan respectively.

Once the vending machine started to work, if it detected the 3 pressed button, it will show the corresponding amount of inserted money, and such amount can be accumulated automatically for display. This time, the upper limit for such amount is set as 20 Yuan.

(3)The design of commodity selection system

The commodity selection system is mainly operated through buttons, the buttons shall be the device for human-machine interaction, it has the inexpensive price and convenient application, and has been used widely in SCM application system already.

Once the vending machine started to work with the inserted money, by pressing the commodity selection button, there will show the matching commodity name on the display, once the multi-choice button was pressed, the display will show the quantity of multi-choice behind the displayed commodity name. 


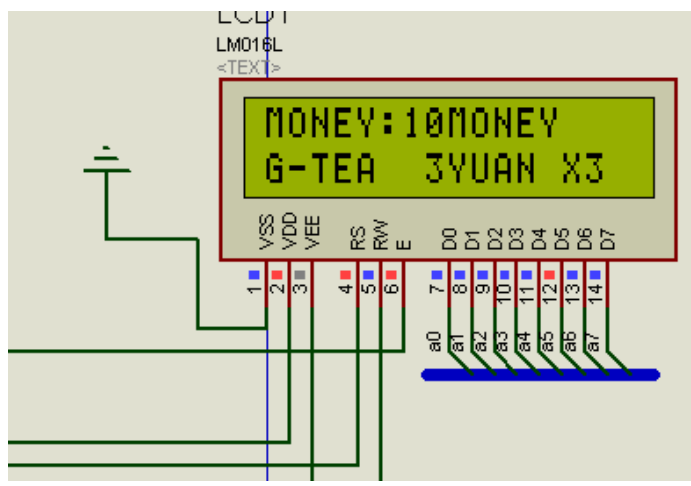

Figure 2 The simulation diagram of money inserting and commodity selection system

(4)The design of commodity delivery system

In this design, the P2.4, P2.3 and P2.2 ports of vending machine connect with the green LED light respectively, once the commodity was selected, the lighted 3 LED lights then respectively represent the commodity delivery of water, G-tea and coffee. And once the quantity of selected commodity was 2,3 or 4 , the LED light then will flash in 2, 3 or 4 times respectively.

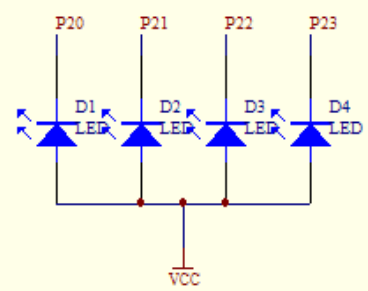

Figure 3. The circuit diagram of commodity delivery system.

(5)The design of display and changing returning system

In this design, the P0 port of vending machine connects with the D0 D7 pins of LCD1602, and the P2.5, P2.6, P2.7 ports connect with the RS, R/W and E pins of LCD1602 respectively, so as to realize the display function. Once the vending machine started to work, the LCD 1602 can display the quantity and amount of inserted money, the name of selected commodity and unit price of the commodity accordingly.

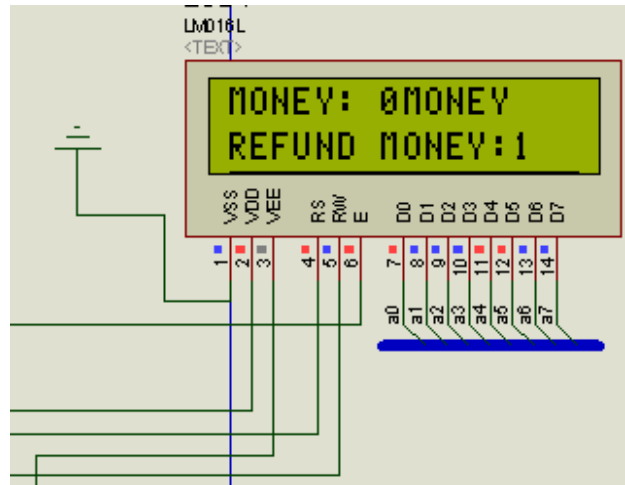

Figure 4. The simulation diagram of change returning system display

(6)The design of warning system

In this design, the P2.0 port of vending machine connects with the red LED and a buzzer. Once the P.0 port was at low level, the LED light will shine accompanied with the sound of buzzer, so as to realize the function of warning system accordingly.

Once the vending machine started to work, the warning system will send the buzzer sound and light the red LED upon the incorrect operation process or the amount of inserted money less than the total value of selected commodities. 


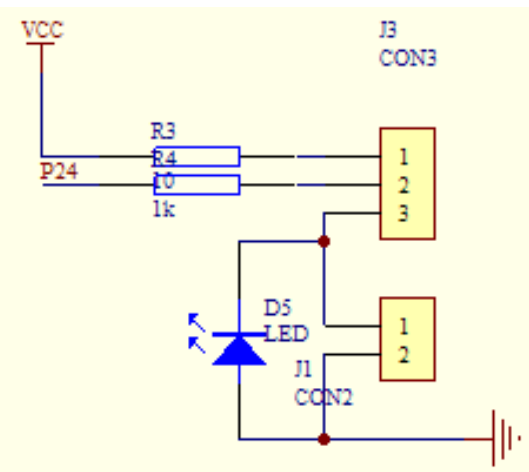

Figure 5. The circuit diagram of warning system

\section{Summary}

This time, through the design of vending machine system based on the AT89S52 control system of SCM, I've improved my own ability for independent study and learned how to comprehensively use learning professional basic knowledge to solve the practical problem, meanwhile it also improved my other professional abilities and levels in literature review, manual design, design specification and computer aided design etc.

This work is supported the following fund:2016 The project of improving the basic ability of young teachers in Colleges and universities in Guangxi: "Design and development of electronic commerce platform of agricultural products based on Semantic Technology" No,KY2016YB455) 2015 college students' innovative training program: "Research on the application of value added travel experience in the mobile terminal of the "ethnic custom travel' in Guangxi" (No 201511838070);\&\& "The design and development HeYuanTong Campus Mobile Phone APP based on Android" (No 201511838034).Project of scientific research and technology development project of Hezhou: "Design and implementation of agricultural products e-commerce platform based on Semantic Technology" (No, Hekeneng 1506006).

\section{References}

[1]. B.Q Li, Y.F Ling, H.Y Zhang, and S.Y Zheng: the design and realization of cherry tomato harvesting robot based on iot. International journal of online engineering, 12(12), 23, (2016).

[2]. B.Q Li, W.L Guan, S.Y Zheng, X.G Yue: optimisation design of corn precision seeder based on multi-route and multi-channel control. Journal of the balkan tribological association, 21(4a), 1215, (2015).

[3]. S.Y Zheng, et al, social work in teen addiction correction services research under the new situation, in: proceedings of the 2015 4th national conference on electrical, electronics and computer engineering (nceece 2015), Xian, china, 2015, pp.252-255.

[4]. B.Q Li, et al, intelligent control management system and its application, in: proceedings of the 2016 international conference on economics and management innovations, Wuhan, china, 2016, pp.68-71.

[5]. B.Q Li, et al, design and implementation of tanks war game based on the android platform, in: proceedings of the 2016 2nd workshop on advanced research and technology in industry applications, Dalian, china, 2016, pp.963-966.

[6]. B.Q Li, et al, design of a tea garden ant freezing control system, in: proceedings of the 2016 6th international conference on machinery, materials, environment, biotechnology and computer (mmebc), Tianjin, china, 2016, pp.736-738.

[7]. B.Q Li, et al, design of electronic compass, in: proceedings of the 2016 6th international conference on machinery, materials, environment, biotechnology and computer (mmebc), Tianjin, china, 2016, pp.1240-1243. 
[8]. B.Q Li, et al, research of automatically light-adjusting lamp, in: proceedings of the 2016 international conference on computer engineering, information science \& application technology (iccia 2016), Guilin, china, 2016, pp.249-252.

[9]. B.Q Li, et al, the design and realization of fruit harvesting robot based on iot, in: proceedings of the 2016 international conference on computer engineering, information science \& application technology (iccia 2016), Guilin, china, 2016, pp.261-264.

[10]. B.Q Li, et al, a new type of automatic opening and closing light-operated curtain, in: proceedings of the 2016 international conference on mechatronics engineering and information technology (icmeit), Xian, china, 2016, pp.66-69.

[11]. B.Q Li, et al, design of the intelligent air humidifier, in: proceedings of the 2016 international conference on mechatronics engineering and information technology (icmeit), Xian, china, 2016, pp.201-203.

[12]. B.Q Li, et al, the design implementation of the app of experiencing Guangxi folk custom, in: proceedings of the 2016 international conference on economics and management innovations, Wuhan, china, 2016, pp.47-50.

[13]. S.Y Zheng, et al, digital display design of ethnic clothing of nailing, in: proceedings of the 4th international conference on mechatronics, materials. Chemistry and computer engineering 2015(icmmcce 2015), Xian, china, 2015, pp.2805-2808.

[14]. S.Y Zheng, et al, design and implementation of supermarket personnel management system based on java, in: proceedings of the 2015 international conference on education, management and computing technology, Tianjin, china, 2015, pp.1724-1727.

[15]. S.Y Zheng, et al, analysis of internet of things talent training and curriculum system innovation, in: proceedings of the 2016 international conference on education, management and computing technology (icemct-16), Hangzhou, china, 2016, pp.957-960.

[16]. S.Y Zheng, et al, brief analysis on "heyuantong" campus mobile phone app design, in: proceedings of the 2015 5th international conference on computer sciences and automation engineering, Sanya, china, 2015, pp.151-154. 